\title{
Dynamic analysis in the Viner model of mercantilism
}

\author{
HENG-FU ZOU* \\ Institute of Advanced Studies, Wuhan University, China and The World \\ Bank, Washington, DC, USA
}

\begin{abstract}
This paper models the central theme of mercantilism in Jacob Viner's interpretation-power vs plenty-in a framework of modern theory of international finance. It is shown that, in the Viner model of mercantilism, a nation with strong mercantilist sentiment ends up with large foreign asset accumulation and high consumption in the long run; an import tariff leads to more foreign asset holding and more total consumption; furthermore, in the Viner model, the Harberger-Laursen-Metzler effect exists unambiguously: a permanent terms-of-trade deterioration causes a current account deficit in the short run. (JEL F1, F3, BO). (C) 1997 Elsevier Science Ltd.
\end{abstract}

This paper offers a mathematical model of mercantilism according to the interpretation by Jacob Viner (1937, 1948, 1968, 1991) while including the interpretations of mercantilism by Schmoller (1897), Cunningham (1907, 1968), and Heckscher $(1935,1955)$ as special cases of the Viner model. Even though mercantilism has been examined, criticized, or even ridiculed since Adam Smith, only recently has a formal model of mercantilism been presented by Irwin (1991) in a framework of the strategic trade theory. To address the central theme of mercantilism, I develop the Viner model of mercantilism in an extended framework of international finance and organize the study as follows.

In section I, I define the utility function of a representative nation on both consumption and foreign asset accumulation to capture 'power vs plenty as objectives' of mercantilism (Viner, 1948, 1991). In this way, a nation derives its power in the international community directly from its possession of wealth.

In section II, I first look at how the mercantilist mentality affects long-run

*Corresponding address: The World Bank, Room N10-075, 1818 H St., N.W. Washington, DC 20433, USA.

I thank Richard Caves, Kala Krishna, Arvind Panagariya, Jeffrey Sachs, and T.N. Srinivasan for their help in various stages of this study. For the revision of this paper, I am most grateful to the two referees for their constructive comments. 
consumption and foreign asset accumulation and show that a nation with strong mercantilist sentiment will have high long-run consumption and foreign asset holdings. Furthermore, an import tariff advocated by mercantilists as a result of their 'fear of goods' (Heckscher, 1955) will lead to more foreign asset accumulation and more total consumption (the sum of domestic goods and foreign goods). Finally, using the Viner model of mercantilism, I show the unambiguous existence of the Harberger-Laursen-Metzler $(\mathrm{H}-\mathrm{L}-\mathrm{M})$ effect: a permanent terms-of-trade deterioration causes a current account deficit in the short run. This finding is significant because so many existing studies have either produced ambiguous results without fully confirming the $\mathrm{H}-\mathrm{L}-\mathrm{M}$ effect or overturned the $\mathrm{H}-\mathrm{L}-\mathrm{M}$ effect.

In section III, I utilize a technique developed by Judd $(1985,1987)$ to analyze the effects of various exogenous shocks on consumption and foreign asset accumulation at the initial equilibrium. In section IV, I summarize the main findings and point out directions for future research.

\section{The Viner model of mercantilism}

This section presents the argument that a direct way to formulate the objective function of the mercantilist economic thinking is to define a nation's utility function on per capita consumption and per capita foreign asset holdings (the accumulated current account surplus):

$$
\int_{0}^{\infty} U\left(c_{h}, c_{f}, b\right) e^{-\rho t} d t=\int_{0}^{\infty}\left[u\left(c_{h}, c_{f}\right)+\beta w(b)\right] e^{-\rho t} d t
$$

where $c_{h}$ is per capita consumption of domestic goods, $c_{f}$ is per capita consumption of foreign goods, $b$ is per capita foreign asset holdings (a negative $b$ is foreign borrowing), and $\beta(\beta>0)$ measures the mercantilist sentiment in the words of Cunningham (1907) or the mercantilist mentality in the words of Heckscher (1955). The variable $b$ can also be broadly defined as 'wealth', 'treasure' and 'riches'. Even in mercantilist heyday, these terms 'were used with considerable ambiguity, sometimes in broad sense to cover stocks of valuable goods of any kind which could command a price, but more often in a narrow sense to signify only the precious metals. The narrow usage was occasionally extended to commodities (other than the precious metals) which had great durability and high value per unit of bulk, such as precious stone, and even tin and copper' (Viner, 1991, p. 263). In the absence of domestic gold or silver mines, mercantilists advocated the attainment of the 'wealth' and 'treasure' through the excess of exports over imports or a current account surplus. The function $\beta w(b)$ can be regarded as the power a nation possesses and enjoys, which is an increasing function of a nation's wealth and asset holdings; the function $u\left(c_{h}, c_{f}\right)$ can be understood as the utility from consumption or as a measure of opulence and plenty in the words of Viner (1948). In its abstract form, the utility function in $\langle 1\rangle$ has been used by Bardhan (1967), Kurz (1968), Blanchard (1983), Zou (1991, 1994b, 1995b) in studying foreign borrowing, capital accumulation, savings and economic growth. 
For a small open economy, the dynamic equation of foreign asset accumulation or the current account is given by:

$$
\dot{b}=\frac{y}{p}+r b-\frac{c_{h}}{p}-(1+\tau) c_{f}+\frac{x}{p},
$$

where $y$ is per capita endowment income, $r$ is the exogneous interest returns on foreign asset holdings, $p$ is the exogenous world relative price of the domestic good in terms of the foreign good, $\tau$ is the tariff on the imported consumption good, $x$ is per capita government transfer. For simplicity, population is assumed to be a constant.

In the existing studies on mercantilism, the objective function of mercantilism has been a controversial topic. Cunningham (1907) has formulated mercantilism mainly as a system of power. In this system, the objective function is the maximisation of the national power, which in turn depends on the wealth and asset holdings possessed by a nation: 'The mercantile system is concerned with man solely as a being who pursue national power' (Heckscher, 1955, vol. 1, p. 29). According to this interpretation, mercantilism has an objective function as maximizing $\int_{0}^{\infty} \beta w(b) e^{-\rho t} d t$ subject to the dynamic constraint given by equation $\langle 2\rangle$. This school does not directly define the utility on consumption because in its interpretation of mercantilism, 'economic well-being and betterment were not defined in terms of or measured by the satisfying of revealed community consumption preferences' (Allen, 1987). In the seventeenth century, 'accumulated wealth was vital, as well as the result of, power. And wealth was intimately associated with specie.... Wealth and specie were closely associated, however, and rising accumulation of gold and silver was taken as reflection of, even if it did not literally constitute, increasing wealth'. Indeed, 'money is the sinews of war' (Allen, 1987).

In this formulation of mercantilism, wealth accumulation through continued trade surplus is only the means to achieve the supreme goal - national power. Heckscher (1955) explicitly states 'Mercantilism as a System of Power' in his study. He has provided some detailed examination why mercantilism subordinates wealth and asset accumulation to power.

Viner $(1948,1991)$ holds a different point of view. His definition of the mercantilist objective can be modeled as exactly in functional form $\langle 1\rangle$ : the mercantilists seek both 'power and plenty (or opulence)'. This is clear from the title of his famous study: 'Power vs Plenty as Objectives of Foreign Policy in the Seventeenth and Eighteenth Centuries'. In addition to seeking plenty or opulence as represented by $u\left(c_{h}, c_{f}\right)$ in the objective function $\langle 1\rangle$, the gain in wealth accumulation also appears explicitly as the term, $r$, in the dynamic equation of the current account $\langle 2\rangle$. Of course, like Cunningham and Heckscher, Viner also emphasize the role of wealth as the foundation of power, which is represented by the function $\beta w(b)$ in equation $\langle 1\rangle$. In Viner's own words: 'I believe that practically all mercantilists, whatever the period, country, or status of the particular individual, would have subscribed to all the following propositions: (1) wealth is an absolutely essential means to power, whether for security or for aggression; (2) power is essential or valuable as a means to the acquisition or retention of wealth; (3) wealth and power are each 
proper ultimate ends of national policy; (4) there is long-run harmony between these ends' (Viner, 1948, 1991, p. 136).

Therefore, our model specified in equations $\langle 1\rangle$ and $\langle 2\rangle$ can be regarded as a synthesis and combination of all these different interpretations of mercantilists' objective functions; in particular, it closely reflects Viner's interpretation of mercantilism.

\section{Some long-run analysis of the model}

Following Bardhan (1967), Kurz (1968), Calvo (1980), Blanchard (1983), and Cole, Mailath and Postlewaite (1992), the function $w(b)$ is assumed to have the following properties: $w^{\prime}>0, w^{\prime \prime} \leq 0$. In addition, $u\left(c_{h}, c_{f}\right)$ is increasing, concave, and continuously differentiable in $c_{h}$ and $c_{f}$, and $\partial^{2} u / \partial c_{h} \partial c_{f}>0$.

The model specified in this paper is an ancient one if it is interpreted with the mercantilist mentality, it is also a modern one if it is viewed as a reflection of today's protectionism, nationalism and international politics and the balance of power. Furthermore, it is a contemporary one because in its mathematical form it is a variation of the standard asset accumulation model in international finance such as Obstfeld $(1981,1982)$ and Turnovsky $(1985,1987)$.

Now I turn to the analysis of the model itself. The home country maximizes $\langle 1\rangle$ subject to $\langle 2\rangle$. The specification of asset accumulation equation $\langle 2\rangle$ is identical to the one in Obstfeld (1982). The objective function differs from that of Obstfeld's paper in two aspects: first, the time discount rate here is constant instead of being an increasing function of the utility; second, the utility function is defined not only on consumption but also on foreign asset accumulation.

To derive the optimal conditions for the home country, I define the presentvalue Hamiltonian as

$$
H=u\left(c_{h}, c_{f}\right)+\beta w(b)+\lambda\left[(y / p)+r b-\left(c_{h} / p\right)-(1+\tau) c_{f}+x / p\right] .
$$

where $\lambda$ is the costate variable.

The first order conditions for maximization are

$$
\begin{gathered}
\partial u / \partial c_{f}=\lambda(1+\tau), \\
\partial u / \partial c_{h}=\lambda / p, \\
\dot{\lambda}=(\rho-r) \lambda-\beta w^{\prime}(b), \\
\dot{b}=(y / p)+r b-\left(c_{h} / p\right)-(1+\tau) c_{f}+(x / p) .
\end{gathered}
$$

From $\langle 4\rangle$ and $\langle 5\rangle$, we can solve $c_{h}$ and $c_{f}$ as functions of $\lambda, p$ and $\tau$

$$
c_{h}=c_{h}(\lambda, p, \tau), \quad c_{f}=c_{f}(\lambda, p, \tau) .
$$

It is easy to show that

$$
\begin{array}{ll}
\partial c_{h} / \partial \lambda<0, & \partial c_{f} / \partial \lambda<0, \quad \partial c_{h} / \partial p>0, \quad \partial c_{f} / \partial p>0 \\
\partial c_{h} / \partial \tau<0, & \partial c_{f} / \partial \tau<0 .
\end{array}
$$


Substitute $c_{h}=c_{h}(\lambda, p, \tau)$ and $c_{f}=c_{f}(\lambda, p, \tau)$ into $\langle 2\rangle$, and rewrite $\langle 6\rangle$ :

$$
\begin{gathered}
\dot{b}=(y / p)+r b-\left[c_{h l}(\lambda, p, \tau) / p\right]-(1+\tau) c_{f}(\lambda, p, \tau)+x / p, \\
\dot{\lambda}=(\rho-r) \lambda-\beta w^{\prime}(b) .
\end{gathered}
$$

Upon introducing a balanced government budget in each period, government transfer $(x / p)$ in our model is exactly equal to its tariff revenue $\tau c_{f}$.

Therefore, equation $\langle 9\rangle$ can be written as

$$
\dot{b}=(y / p)+r b-\left[c_{h}(\lambda, p, \tau) / p\right]-c_{f}(\lambda, p, \tau) .
$$

Equations $\langle 6\rangle$ and $\left\langle 9^{\prime}\right\rangle$ are the focus of our analysis. The necessary condition for the existence of a steady state is that in $\langle 6\rangle$ the time discount rate needs to be greater than the interest rate

$$
\rho>r \text {. }
$$

This condition is also required for the finite horizon model in Blanchard (1985). Note that the introduction of the mercantilist instinct $\beta w(b)$ into our model avoids the knife-edge problem that, for an equilibrium to exist, the time discount rate has to equal the interest rate. In our model, the requirement $\langle 10\rangle$ makes sense because asset accumulation not only bring about interest income $r$ and 'opulence', it also directly gives rise to utility $\beta w^{\prime}(b)$ and 'power', to use the terms used by Eli Heckscher and Jacob Viner. Thus in equilibrium the time discount rate should be larger than the interest rate but equal to the sum of the interest rate and the marginal utility of the power. One attractive feature about our formulation is that it enables us to get away from imposing the equality $\rho=r$, which is so common in much of international macroeconomics. Another way to break this link is to introduce quadratic costs of holding foreign bonds as in Turnovsky (1985). We also note that equation $\langle 6\rangle$ is quite similar to the corresponding dynamic equation in Turnovsky (1985).

Denoting the steady-state values of $\lambda$ and $b$ as $\lambda^{*}$ and $b^{*}$, and linearizing $\langle 6\rangle$ and $\left\langle 9^{\prime}\right\rangle$ around $\lambda^{*}$ and $b^{*}$, we obtain

$$
\left[\begin{array}{l}
\dot{\lambda} \\
\dot{b}
\end{array}\right]=\left[\begin{array}{cc}
\rho-r & -\beta w^{\prime \prime}\left(b^{*}\right) \\
-\left[\left(\partial c_{h} / \partial \lambda\right) / p\right]+\partial c_{f} / \partial \lambda & r
\end{array}\right]\left[\begin{array}{l}
\lambda-\lambda^{*} \\
b-b^{*}
\end{array}\right] .
$$

Let $M$ denote the $2 \times 2$ matrix, and $\Delta^{\prime}$ its determinant,

$$
\Delta^{\prime}=\operatorname{det}(M)=(\rho-r) r-\beta w^{\prime \prime}\left(b^{*}\right)\left\{\left[\left(\partial c_{h} / \partial \lambda\right) / p\right]+\left(\partial c_{f} / \partial \lambda\right)\right\} .
$$

The equilibrium is saddle-point stable if the determinant is negative, namely,

$$
\Delta^{\prime}<0 \text {. }
$$

In this case, there exists a unique perfect-foresight path converging to the equilibrium because one eigenvalue of the dynamic system is negative and one eigenvalue positive. These eigenvalues correspond to one state variable $b$ and one jumping variable $c$ in the model. If $\Delta^{\prime}$ is positive, there will be two positive eigenvalues since the trace of the matrix $M$, which is the sum of the two 
eigenvalues, is also positive and equals the time discount rate $\rho$; that is to say, at least one eigenvalue is positive. But a positive determinant of the matrix $M$ implies that the dynamic system either has two positive eigenvalues or two negative eigenvalues. Thus a positive trace plus a positive determinant of matrix $M$ will result in two positive eigenvalues and a totally unstable system, which will not be considered in this paper.

With the assumption in $\langle 12\rangle$, we draw the phase diagram in Figure 1.

In Figure 1, both curves are downward sloping. Condition $\langle 12\rangle$ is exactly the same as requiring that the slope of the curve $\dot{\lambda}=0$ be steeper than the curve $\dot{b}=0$ in order to have a unique saddle point path converging to the equilibrium A where $b=b^{*}$, and $\lambda=\lambda^{*}$.

\section{A. The effect of the mercantilist mentality}

To see how the mercantilist mentality $\beta$, affects asset accumulation and consumption in the long run, I set $\dot{\lambda}$ and $b$ equal to zero in equation $\left\langle 9^{\prime}\right\rangle$ and $\langle 6\rangle$, and totally differentiate the two steady-state equations

$$
M\left[\begin{array}{c}
d \lambda \\
d b
\end{array}\right]=\left[\begin{array}{c}
w^{\prime}\left(b^{*}\right) d \beta \\
\left\{\left[\left(\partial c_{h} / \partial \tau\right) / p\right]+\left(\partial c_{f} / \partial \tau\right)\right\} d \tau+\left\{\left[\left(y-c_{h}\right) / p^{2}\right]\right. \\
\left.+\left[\left(\partial c_{h} / \partial p\right) / p\right]+\partial c_{f} / \partial p\right\} d p
\end{array}\right]
$$

where $M$ is the same $2 \times 2$ matrix in $\langle 10\rangle$.

Proposition 1: The stronger the mercantilist sentiment, the larger the long-run consumption and asset accumulation.

From $\langle 13\rangle$ and $\langle 12\rangle$

$$
d \lambda / d \beta<0, \quad d b / d \beta>0, \quad d c_{h} / d \beta>0, \quad d c_{f} / d \beta>0,
$$

where we have used the fact that both $\partial c_{h} / \partial \lambda$ and $\partial c_{f} / \partial \lambda$ are negative as in $\langle 8\rangle$.

The reason for this proposition is quite clear. As a nation highly values its wealth and power in the world, it saves more and consumes less in the short run in order to run a current account surplus and accumulate more foreign assets. More foreign asset holdings means more interest income, which in turn leads to more consumption in the long run. Proposition 1 is a very strong argument for mercantilism if a nation intends to maximize its citizens' long-run consumption.

\section{II.B. The effect of the tariff}

The effect of the tariff can be seen by Cramer's rule in $\langle 13\rangle$

$$
\begin{gathered}
d \lambda / d \tau=\beta w^{\prime \prime}\left(b^{*}\right)\left\{\left[\left(\partial c_{h} / \partial \tau\right) / p\right]+\left(\partial c_{f} / \partial \tau\right)\right\} / \Delta^{\prime}<0, \\
d b / d \tau=(\rho-r)\left\{\left[\left(\partial c_{h} / \partial \tau\right) / p\right]+\left(\partial c_{f} / \partial \tau\right)\right\} / \Delta^{\prime}>0
\end{gathered}
$$




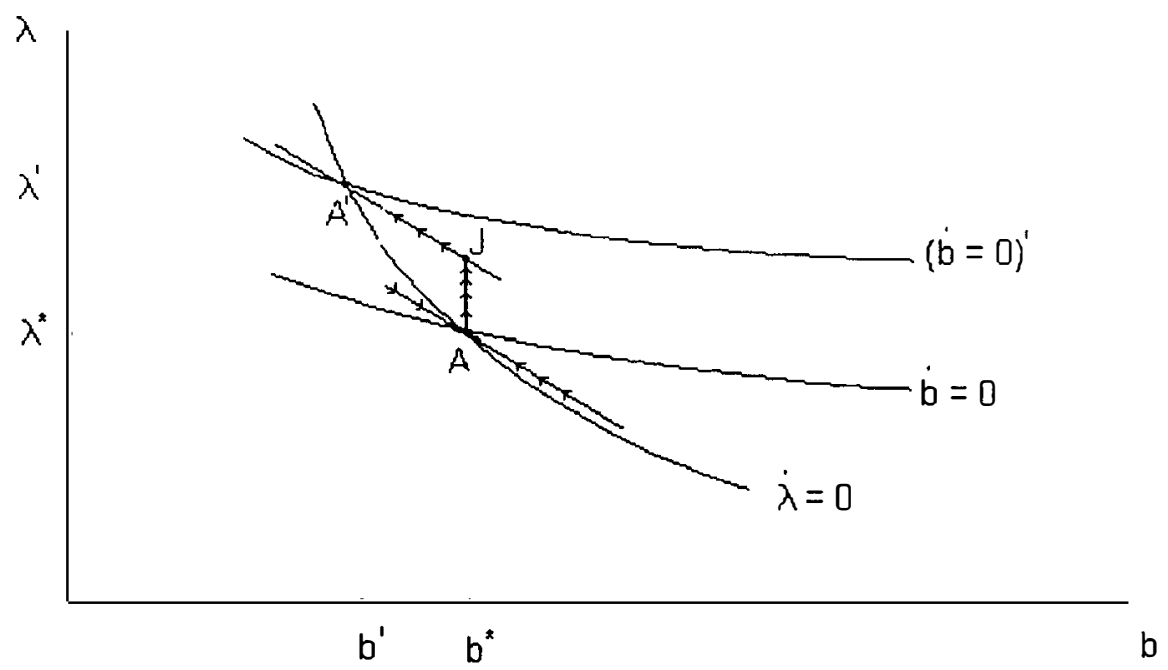

FigurE 1. The phase diagram and the effect of a permanent terms-of-trade deterioration.

Proposition 2: A permanent increase in the tariff rate raises the total long-run consumption and asset accumulation.

The positive effect of the tariff on asset accumulation is in $\langle 15\rangle$. To see its effect on long-run consumption, we note that a tariff directly reduces the consumption of both domestic and imported goods, but it also leads to a lower shadow price $\lambda$, which increases consumption. The net effect is positive because, from the steady state equation, $\dot{b}=0$, namely,

$$
(y / p)+r b^{*}-\left[c_{h}^{*}\left(\lambda^{*}, \tau\right) / p\right]-c_{f}^{*}\left(\lambda^{*}, \tau\right)=0
$$

a higher tariff increases $b^{*}$ and total interest income. Therefore, to maintain the equilibrium condition in the goods market, total consumption will have to rise in the long run, even though the impact on the consumption of the foreign good is ambiguous.

Proposition 2 provides support for the mercantilist protection policy, namely, the 'fear of goods' (Heckscher, 1955), if attainment of a higher long-run consumption is the national objective. Both proposition 1 and proposition 2 indicate the long-run harmony between wealth and power. Indeed, from the mercantilist perspective, 'there is long-run harmony between these two ends, although in particular circumstances it may be necessary for a time to make economic sacrifices in the interest of ... 'long-run prosperity' (Viner, 1991, p. 136). Following an increase in the tariff, short-run consumption will be cut because people invest more in foreign asset. But in the long run, the increased foreign asset accumulation gives rise to more consumption and more power for the nation.

We should emphasize that proposition 2 is derived in a pure endowment economy without market imperfection and increasing returns to scale in production. In the strategic trade theory, protectionist economic policies are often justified with the presence of product differentiation on the demand side 
and externalities on the production side. In the mercantilist model, protectionist economic policy such as a tariff leads to a higher long-run asset accumulation and consumption in a world without any imperfection on either the demand side or the supply side. Proposition 2 therefore sheds some insight on the protectionist economic policies in addition to the ones offered by the strategic trade theory.

\section{II.C. The effect of a terms-of-trade shock}

Since Obstfeld (1982) raised the doubt about the existence of the Harberger-Laursen-Metzler $(\mathrm{H}-\mathrm{L}-\mathrm{M})$ effect in an infinite horizon model with an endogneous time preference, many contributions over the past decade have explored this issue. But perhaps it is a surprise that, while Obstfeld overturned the $\mathrm{H}-\mathrm{L}-\mathrm{M}$ effect, all other models have only produced ambiguous results on the existence of the $\mathrm{H}-\mathrm{L}-\mathrm{M}$ effect under various assumptions and model strategies. For example, Svensson and Razin (1983) have examined the effect of terms-of-trade changes on a small country's consumption and current account in an intertemporal model. They demonstrate that a temporary (future) terms-of-trade deterioration implies a deterioration (improvement) of the trade balance, whereas a permanent terms-of-trade deterioration has an ambiguous effect, depending on the rate of time preference. In another contribution by Persson and Svensson (1985), it is shown that the classic H-L-M effect can have any sign for plausible parameter values, both for temporary and permanent disturbance. Ambiguities have also been shown in various models by Matsuyama (1987), Sen and Turnovsky (1989), and Mansoorian (1993).

Here it can be shown that, in the Viner model of mercantilism, there exists a full confirmation of the $\mathrm{H}-\mathrm{L}-\mathrm{M}$ effect: an unanticipated permanent deterioration in the terms of trade always leads to a current account deficit in the short run. Suppose that the economy is in the steady state A of Figure 1, and the terms of trade worsen permanently, i.e. $p$ goes up forever. Then, in Figure 1, the curve $\dot{\lambda}=0$ does not change, but the curve $\dot{b}=0$ shifts upward to $(\dot{b})^{\prime}=0$. Immediately following the shock, $\lambda$ jumps up from the initial equilibrium point $A$ to point $J$. Since foreign asset holdings are the state variable, $b$ cannot jump. Therefore, at the time when this permanent shock happens, consumption will be cut immediately and the current account goes to surplus (we will provide a quantitative estimate for this initial change in consumption and the current account in the next section). But after the initial shock, along the convergent path from point $J$ to the new equilibrium $A^{\prime}$, foreign asset holding $b$ decreases and the current account goes to a deficit in the short run or during the adjustment period. At the same time, $\lambda$ continues to increase, and, from $\langle 8\rangle$, the consumption of both the home good and imported good is decreasing. In the new steady state $A^{\prime}$, the economy has smaller foreign asset holdings than before: $b^{\prime}<b^{*}$.

Analytically, by Cramer's rule in $\langle 13\rangle$,

$$
d \lambda / d p=\left[\beta w^{\prime \prime}\left(b^{*}\right) / \Delta^{\prime}\right]\left\{\left[\left(y-c_{h}\right) / p^{2}\right]+\partial c_{f} / \partial p+\left(\partial c_{h} / \partial p\right) / p\right\}>0,
$$


which is positive because $w^{\prime \prime}<0, \Delta^{\prime}<0,\left(y-c_{h}\right) \geq 0$ (as the endowment of the home goods is no less than the consumption of the home goods), and, from $\langle 8\rangle, \partial c_{h} / \partial p>0$, and $\partial c_{i} / \partial p>0$. Almost by the same reason,

$\langle 17\rangle$

$$
d b / d p=\left[(\rho-r) / \Delta^{\prime}\right]\left\{\left[\left(y-c_{h}\right) / p^{2}\right]+\lambda c_{i} / \partial p+\left(i c_{h} / \partial p\right) / p\right\}<0,
$$

and note that $\rho>r$ in order to have a steady state as we stated earlier in condition $\langle 12\rangle$. Therefore,

Proposition 3: The $\mathrm{H}-\mathrm{L}-\mathrm{M}$ effect always holds in the Viner model of mercantilism.

The economic explanation for proposition 3 is as follows: a permanent deterioration of the terms of trade reduces the small economy's income, the home country responds to this permanent shock by lowering its consumption immediately following the shock. Since the preference is directly defined on both consumption and foreign asset holdings, a lower consumption with unchanged foreign asset holdings upsets the initial equilibrium condition between consumption and foreign asset holdings. Therefore, the home country will convert part of its foreign asset holdings into consumption because consumption is now more valuable than foreign asset. In the short run, the current account goes to a deficit, and, in the long run, foreign asset accumulation is reduced. Thus in the Viner model of mercantilism, the $\mathrm{H}-\mathrm{L}-\mathrm{M}$ effect always holds. This confirmation of the $\mathrm{H}-\mathrm{L}-\mathrm{M}$ effect as a result of a permanent terms-of-trade deterioration stands in sharp contrast to the Obstfeld model; it is also a clear-cut result without the ambiguities presented in so many existing studies. In passing, we shall note that the ambiguities may continue when the mercantilist model is extended to include capital accumulation and variable rate of time preference.

\section{The impacts of various shocks at the initial equilibrium}

In this section, it is assumed that the home country is in an equilibrium at time $t=0$. In order to examine the effects of various shocks on consumption and the current account at this initial equilibrium, I follow a technique developed by Judd (1985, 1987). A different analysis of the current account in a finite horizon model is presented in Zou (1994a).

Suppose that at time $t=0$, i.e. today, the economy is in the steady state $b^{*}$ and $\lambda^{*}$ corresponding to the initial terms of trade $p^{*}$, the initial tariff rate $\tau^{*}$, the initial interest rate $r^{*}$, and the initial mercantilist sentiment $\beta^{*}$. Also at time $t=0$, the terms of trade, the tariff rate, the interest rate, and the mercantilist sentiment change as follows

$$
\begin{aligned}
& p^{\prime}=p^{*}+\varepsilon p(t), \quad \tau^{\prime}=\tau^{*}+\varepsilon \tau(t), \quad r^{\prime}=r^{*}+\varepsilon r(t), \\
& \beta^{\prime}=\beta^{*}+\varepsilon \beta(t),
\end{aligned}
$$

where $\varepsilon$ is a parameter and functions $p(t), \tau(t), r(t)$ and $\beta(t)$ represent the intertemporal changes of various parameters in a magnitude-free fashion since 
$\varepsilon$ can represent different magnitude of change. For example, a change in the terms of trade during a future time $T_{1}<t<T_{2}$ can be represented by setting $p(t)$ to be one for $T_{1}<t<T_{2}$ and zero otherwise. In this way, $p(t)$ can be regarded as a step function.

Substituting $p^{\prime}, \tau^{\prime}, r^{\prime}$ and $\beta^{\prime}$ into equations $\langle 6\rangle$ and $\left\langle 9^{\prime}\right\rangle$ yields

$$
\dot{\lambda}=\left(\rho-r^{*}-\varepsilon r(t)\right) \lambda-\left(\beta^{*}+\varepsilon \beta(t)\right) w^{\prime}(b),
$$

$$
\begin{aligned}
\dot{b}= & {\left[y /\left(p^{*}+\varepsilon p(t)\right)\right]-c_{f}\left(\lambda, p^{*}+\varepsilon p(t), \tau^{*}+\varepsilon \tau(t)\right) } \\
& -\left[c_{h}\left(\lambda, p^{*}+\varepsilon p(t), \tau^{*}+\varepsilon \tau(t)\right) /\left(p^{*}+\varepsilon p(t)\right)\right]+\left(r^{*}+\varepsilon r(t)\right) b .
\end{aligned}
$$

The solutions for $b$ and $\lambda$ will depend on both $t$ and $\varepsilon$. I write the solutions as $b(t, \varepsilon)$ and $\lambda(t, \varepsilon)$. Since $\varepsilon=0$ implies that the system remains at the initial steady state, the effects of a terms-of-trade change can be seen from the impact on the paths of $b$ and $\lambda$ as $\varepsilon$ varies from zero to a small positive or negative value. Formally, I define the initial impacts of $\varepsilon$ on $b$ and $\lambda$ here:

$$
\begin{array}{ll}
b_{\varepsilon}(t)=\partial b(t, 0) / \partial \varepsilon, & \lambda_{\varepsilon}(t)=\partial \lambda(t, 0) / \partial \varepsilon, \\
\dot{b}_{\varepsilon}(t)=\partial[\partial b(t, 0) / \partial \varepsilon] / \partial t, & \dot{\lambda}_{\varepsilon}(t)=\partial[\partial \lambda(t, 0) / \partial \varepsilon] / \partial t .
\end{array}
$$

Differentiating equation $\langle 19\rangle$ and $\langle 20\rangle$ with respect to $\varepsilon$ and evaluating the derivatives at $\varepsilon=0$ yield a pair of differential equations in the variables $b_{\varepsilon}$ and $\lambda_{\varepsilon}$

$$
\left[\begin{array}{l}
\dot{\lambda}_{\varepsilon} \\
\dot{b}_{\varepsilon}
\end{array}\right]=\left[\begin{array}{cc}
\rho-r & -\beta w^{\prime \prime}\left(b^{*}\right) \\
-\left[\partial c_{f} / \partial \lambda+\left(\partial c_{h} / \partial \lambda\right) / p^{*}\right] & r
\end{array}\right]\left[\begin{array}{l}
\lambda_{\varepsilon} \\
b_{\varepsilon}
\end{array}\right]+\left[\begin{array}{l}
v_{1}(t) \\
v_{2}(t)
\end{array}\right],
$$

where

$$
\begin{gathered}
\left\langle v_{1}(t)=-\lambda^{*} r(t)-w^{\prime}\left(b^{*}\right) \beta(t)\right. \\
\langle 23\rangle \quad v_{2}(t)=b^{*} r(t)-\left\{\left(\partial c_{f} / \partial \tau\right)+\left[\left(\partial c_{h} / \partial \tau\right)\left(1 / p^{*}\right)\right]\right\} \tau(t) \\
-\left\{\left[\left(y-c_{h}\right) / p^{* 2}\right]+\left(\partial c_{f} / \partial p\right)+\left[\left(\partial c_{h} / \partial p\right)\left(1 / p^{*}\right)\right\} p(t) .\right.
\end{gathered}
$$

the coefficient for $p(t)$ is always negative because $\left(y-c_{h}\right)$ is positive as the home goods endowment is no less than the home goods consumption, $\partial c_{f} / \partial p$ and $\partial c_{h} / \partial p$ are both positive from $\langle 8\rangle$.

Let me continue to denote the determinant of the Jacobian matrix in $\langle 21\rangle$ as $\Delta^{\prime}$. Then, for a saddle-point equilibrium, the positive and negative eigenvalues for the Jacobian matrix are given by $\mu$ and $\omega$, respectively

$$
\begin{aligned}
& \mu=\left[\rho+\sqrt{\rho^{2}-4 \Delta^{\prime}}\right] / 2>0, \\
& \omega=\left[\rho-\sqrt{\rho^{2}-4 \Delta^{\prime}}\right] / 2<0 .
\end{aligned}
$$

As in Judd (1985, 1987), the Laplace transform can be utilized to solve equation $\langle 21\rangle$. For sufficiently large positive $s$, the Laplace transform of a 
function $f(t)(t>0)$ is another function $F(s)$, where

$$
F(s)=\int_{0}^{\infty} f(t) e^{-s t} \mathrm{~d} t
$$

Let $\Lambda_{\varepsilon}(s), B_{\varepsilon}(s), R(s), T(s), P(s)$ and $H(s)$ be the Laplace transforms of $\lambda_{\varepsilon}(t), b_{t:}(t), r(t), \tau(t), p(t)$ and $\beta(t)$, respectively. Then

$$
s\left[\begin{array}{l}
\Lambda_{\varepsilon} \\
B_{\varepsilon}
\end{array}\right]=\left[\begin{array}{cc}
\rho-r & -\beta w^{\prime \prime}\left(b^{*}\right) \\
-\left[\partial c_{f} / \partial \lambda+\left(\partial c_{h_{l}} / \partial \lambda\right) / p^{*}\right] & r
\end{array}\right]\left[\begin{array}{l}
\Lambda_{\varepsilon} \\
B_{\varepsilon}
\end{array}\right]+\left[\begin{array}{c}
V_{1}(s)+\lambda_{\varepsilon}(0) \\
V_{2}(s)+b_{\varepsilon}(0)
\end{array}\right],
$$

where

$$
\begin{aligned}
V_{1}(s)= & -\lambda^{*} R(s)-w^{\prime}\left(b^{*}\right) H(s) \\
V_{2}(s)= & b^{*} R(s)-\left\{\left(\partial c_{f} / \partial \tau\right)+\left[\left(\partial c_{h} / \partial \tau\right)\left(1 / p^{*}\right)\right]\right\} T(s) \\
& -\left\{\left[\left(y-c_{h}\right) / p^{* 2}\right]+\left(\partial c_{f} / \partial p\right)+\left[\left(\partial c_{h} / \partial p\right)\left(1 / p^{*}\right)\right\} P(s) .\right.
\end{aligned}
$$

Solving for $\Lambda_{\varepsilon}(s)$ and $B_{\varepsilon}(s)$ in $\langle 26\rangle$

$$
\left[\begin{array}{l}
\Lambda_{\varepsilon} \\
B_{\varepsilon}
\end{array}\right]=\left[\begin{array}{cc}
s-\rho+r & \beta w^{\prime \prime}\left(b^{*}\right) \\
{\left[\partial c_{f} / \partial \lambda+\left(\partial c_{h} / \partial \lambda\right) / p^{*}\right]} & s-r
\end{array}\right]^{-1}\left[\begin{array}{c}
V_{1}(s)+\lambda_{\varepsilon}(0) \\
V_{2}(s)
\end{array}\right] .
$$

I have dropped $b_{\varepsilon}(0)$ in equation $\langle 27\rangle$ because $b$ is the state variable and the initial foreign asset $b(0)$ cannot be altered immediately. But the costate variable $\lambda$ can jump and the jump is necessary to assure the convergence of the two variables on the perfect foresight path. To pin down the initial jump in $\lambda$, namely, $\lambda_{\varepsilon}(0)$, it is noted that the existence of a saddle-point equilibrium implies a bounded steady state foreign asset accumulation for any $\varepsilon$. Therefore, $B_{\varepsilon}(s)$ must be finite for all $s>0$, even for $s=\mu$ (the positive eigenvalue of the dynamic system). However, when $s=\mu$, the $2 \times 2$ matrix in $\langle 27\rangle$ is singular and its inverse does not exist. To remove this singularity, implicitly the numerators on the right hand side have to be zero because the denominator is equal to $(s-\mu)(s-\omega)$, which is zero when $s=\mu$. That is to say

$$
(\mu-r)\left[V_{1}(\mu)+\lambda_{\varepsilon}(0)\right]-\beta w^{\prime \prime}\left(b^{*}\right) V_{2}(\mu)=0 \text {. }
$$

From $\langle 28\rangle$, I have

$$
\begin{aligned}
\lambda_{\varepsilon}(0)= & -V_{1}(\mu)+\beta w^{\prime \prime}\left(b^{*}\right) V_{2}(\mu)(\mu-r)^{-1} \\
= & -\lambda^{*} R(\mu)-w^{\prime}\left(b^{*}\right) H(\mu)+\beta w^{\prime \prime}\left(b^{*}\right)(\mu-r)^{-1}\left\{b^{*} R(\mu)-\left\{\left(\partial c_{f} / \partial \tau\right)\right.\right. \\
& \left.+\left[\left(\partial c_{h} / \partial \tau\right)\left(1 / p^{*}\right)\right]\right\} T(\mu)-\left\{\left[\left(y-c_{h}\right) / p^{* 2}\right]+\left(\partial c_{f} / \partial p\right)\right. \\
& \left.+\left[\left(\partial c_{h} / \partial p\right)\left(1 / p^{*}\right)\right\} P(\mu)\right\} .
\end{aligned}
$$

Since $P(\mu)$ is just the present value of future terms-of-trade shock discounted at the positive eigenvalue: $P(\mu)=\int_{0}^{\infty} p(t) e^{-\mu t} d t$, the initial jump in the shadow 
price of the foreign asset is always positively related to the discounted, future terms-of-trade shock because the coefficient of $P(\mu)$ in $\langle 29\rangle$ is always positive.

With the information of $\lambda_{\varepsilon}(0)$, I can substitute both $\lambda_{\varepsilon}(0)$ and $b_{\varepsilon}(0)$ (the latter is always zero) into equation $\langle 21\rangle$ and find out the responses of the initial current account to various shocks

$$
\begin{aligned}
\dot{b}_{\varepsilon}(0)= & -\left\{\left(\partial c_{f} / \partial \lambda\right)+\left[\left(\partial c_{h} / \partial \lambda\right)\left(1 / p^{*}\right)\right]\right\} \lambda_{\varepsilon}(0)+V_{2}(0) \\
= & -\left\{\left(\partial c_{f} / \partial \lambda\right)+\left[\left(\partial c_{h} / \partial \lambda\right)\left(1 / p^{*}\right)\right]\right\}\left\{-\lambda^{*} R(\mu)-w^{\prime}\left(b^{*}\right) H(\mu)\right. \\
& +\beta w^{\prime \prime}\left(b^{*}\right)(\mu-r)^{-1}\left\{b^{*} R(\mu)-\left\{\left(\partial c_{f} / \partial \tau\right)+\left[\left(\partial c_{h} / \partial \tau\right)\left(1 / p^{*}\right)\right]\right\} T(\mu)\right. \\
& \left.-\left\{\left[\left(y-c_{h}\right) / p^{* 2}\right]+\left(\partial c_{f} / \partial p\right)+\left[\left(\partial c_{h} / \partial p\right)\left(1 / p^{*}\right)\right\} P(\mu)\right\}\right\} \\
& +b^{*} r(0)-\left\{\left(\partial c_{f} / \partial \tau\right)+\left[\left(\partial c_{h} / \partial \tau\right)\left(1 / p^{*}\right)\right]\right\} \tau(0) \\
& -\left\{\left[\left(y-c_{h}\right) / p^{* 2}\right]+\left(\partial c_{f} / \partial p\right)+\left[\left(\partial c_{h} / \partial p\right)\left(1 / p^{*}\right)\right\} p(0) .\right.
\end{aligned}
$$

From $\langle 30\rangle$, a few observations can be derived.

First, if the initial equilibrium asset holdings are positive, then any future increase in the interest rate results in a current account deficit today

$$
\begin{aligned}
d \dot{b}_{\varepsilon}(0) / d R(\mu)= & -\left\{\left(\partial c_{f} / \partial \lambda\right)+\left[\left(\partial c_{h} / \partial \lambda\right)\left(1 / p^{*}\right)\right]\right\} \\
& \times\left\{-\lambda^{*}+\beta w^{\prime \prime}\left(b^{*}\right)(\mu-r)^{-1} b^{*}\right\}<0,
\end{aligned}
$$

which is negative if the steady-state asset accumulation $b^{*}$ is positive. This is true because any future rise in the interest rate leads to more future income for the home country. To smooth its consumption, the home country spends more today by cutting its current asset holding. Thus, the current account deteriorates today.

Second, a rise in the mercantilist mentality $\beta$ in the future drives today's current account to a deficit

$$
d \dot{b}_{\varepsilon}(0) / d H(\mu)=\left\{\left(\partial c_{f} / \partial \lambda\right)+\left[\left(\partial c_{h} / \partial \lambda\right)\left(1 / p^{*}\right)\right]\right\} w^{\prime}\left(b^{*}\right) H(\mu)<0 .
$$

This result makes sense because a rise in $\beta$ in the future will increase asset holdings and raises future income. Therefore, to smooth consumption, the home country increases its consumption today. The rising consumption without a corresponding increase in current income worsens the trade balance and the current account today.

Third, a higher tariff in the futue has a negative impact on the current account today (note that $(\mu-r)>0$ in equation $\langle 30\rangle$ ). This result holds because a future rise in the tariff leads to more asset accumulation and more income in the future (see proposition 2). Thus, to smooth consumption, the home country converts part of its current asset holdings to current consumption. In this way, today's current account goes to a deficit.

Fourth, any future deterioration (improvement) in the terms of trade improves (worsens) the current account today. (To see this, note that the 
coefficient for $P(\mu)$ in $\langle 30\rangle$ is always positive.) The economic intuition behind this observation is as follows: a future deterioration in the terms of trade reduces future income. The home country reacts to this anticipated future shock by cutting its consumption today. As shown in proposition 3 , the long-run foreign asset holdings will also be reduced if the shock is permanent. But in the very short run, the foreign asset holding is a state variable, which cannot jump down immediately. Thus only consumption will be reduced. This is shown as the jump from point $A$ to point $J$ in Figure 1. In the transition from point $J$ to point $A^{\prime}$ in Figure 1, both consumption and foreign asset holdings are reduced as a result of a permanent terms-of-trade shock.

Fifth, a current rise in the interest rate and the tariff rate improves today's current account while a current deterioration in the terms of trade worsens the current account today. Thus, the effects of all these current shocks on today's current account are just the opposite of the ones of future shocks. A current rise in the interest rate leads to more income today and improves today's current account; a current rise in the tariff reduces consumption and increases trade surplus; finally, a deterioration in the terms of trade today, i.e. $p(0)$ increases, lowers the home country's income today and worsens its current account because a momentary income reduction as a result of the terms-of-trade shock will not affect current consumption of both home goods and imported goods.

\section{Conclusions}

This paper has formulated Jacob Viner's interpretation of mercantilism by defining both consumption and foreign asset accumulation in the utility function to reflect power vs plenty as objectives of a mercantilist nation. This model also has various applications and interpretations: nationalism in the sense of Bardhan (1967); the psychological benefit (costs) of foreign asset holdings (foreign borrowing) in the sense of Blanchard (1983); the wealth-is-status model in Frank (1985), Cole et al. (1992), and Fershtman and Weiss (1993); and the capitalist-spirit model as in Zou (1994b, 1995b) and Bakshi and Chen (1996).

The most interesting, and perhaps surprising fact about this Viner model of mercantilism is its theoretical predictions. We have shown that in the Viner model a nation with strong mercantilist sentiment has high consumption and large foreign asset accumulation in the long run; a permanent rise in the tariff rate leads to more foreign asset accumulation and more total consumption in the long run; a permanent terms-of-trade shock worsens the current account in the short run, which provides a full confirmation of the existence of the $\mathrm{H}-\mathrm{L}-\mathrm{M}$ effect in an infinite horizon model.

In future research, it is desirable to extent the endowment-economy and small-economy model in this paper into a big-country model with both capital accumulation and foreign asset holdings. It should also be interesting to study fiscal policy, monetary policy and the exchange-rate theory in the Viner model of mercantilism. Furthermore, the mercantilist model can be extended to consider the relative wealth or relative power status in a many-country world as 
in Bakshi and Chen (1996), where the utility function from wealth and power is modified to be $\beta w(b(t) / B(t))$ with $B(t)$ as the average wealth level in the rest of the world.

\section{References}

Allen, W. (1987) Mercantilism. In The New Palgrave: A Dictionary of Economics. Macmillan, London.

Bakshi G. and Chen, Z. (1996) The spirit of capitalism and stock market prices. American Economic Review 86, 133-157.

Bardhan, P. (1967) Optimum foreign borrowing. In: Essays on the Theory of Optimal Economic Growth, ed K. Shell. MIT Press.

Blanchard, O. (1983) Debt and current account deficit in Brazil. In: Financial Policies and the World Capital Market, eds A. Armella et al. University of Chicago Press, Chicago.

Blanchard, O. (1995) Debt, deficits and finite horizons. Journal of Political Economy 93, 223-247.

Calvo, G. (1980) Financial Opening, Crawling Peg and the Real Exchange Rate, mimeo.

Cole, H., Mailath, G. and Postlewaite, A. (1992) Social norms, savings behavior, and growth. Journal of Political Economy 100, 1092-1125.

Cunningham, W. (1968) The Growth of English Industry and Commerce and Modern Times: The Mercantile System, 4th edn., 1907; reprinted by A. M. Kelley Publishers, New York.

Fershtman, C. and Weiss, Y. (1993) Social status, culture and economic performance. Economic Journal 103, 946-959.

Frank, R. (1985) Choosing the Right Pond: Human Behavior and the Quest for Status. Oxford University Press.

Heckscher, E., (1934, 1955) Mercantilism, Vol. 2. Allen \& Unwin (2nd edn).

Irwin, D. (1991) Mercantilism as strategic trade policy: the Anglo-Dutch rivalry for the East India trade. Journal of Political Economy 99, 1296-1314.

Judd, K. (1985) Short-run analysis of fiscal policy in a simple perfect foresight model. Journal of Political Economy 93, 298-319.

Judd, K. (1987) Debt and distortionary taxation in a simple perfect foresight model. Journal of Monetary Economics 20, 51-72.

Kurz, M. (1968) Optimal economic growth and wealth effects. International Economic Review 9, 348-357.

Matsuyama, K. (1987) Current account dynamics in a finite horizon model. Journal of International Economics 23, 299-313.

Mansoorian, A. (1993) Habit persistence and the Harberger-Laursen-Metzler effect in an infinite horizon model. Journal of International Economics 34, 153-166.

Obstfeld, M. (1981) Macroeconomic policy, exchange-rate dynamics, and optimal asset accumulation. Journal of Political Economy 89, 1142-1161.

Obstfeld, M. (1982) Aggregate spending and the terms of trade: is there a Laursen-Metzler effect? Quarterly Journal of Economics 97, 251-270.

Persson, T. and Svensson, L.E.O. (1985) Current account dynamics and the terms of trade. Journal of Political Economy 93, 43-65.

Schmoller, G. (1897) The Mercantile System and its Historical Significance, Illustrated Chiefly from Prussian History, Macmillan, New York.

Schumpeter, J. (1954) History of Economic Analysis. Oxford University Press.

Sen, P. and Turnovsky, S. J. (1989) Deterioration of the terms of trade and capital accumulation. Journal of International Economics 26, 227-250. 
Svensson, L.E.O. and Razin. A. (1983) The terms of trade and the current account. Journal of Political Economy 91, 97-125.

Turnovsky, S. (1985) Domestic and foreign disturbances in an optimizing model of exchange-rate determination. Journal of International Money and Finance, 4, 151-171.

Turnovsky, S. (1987) Optimal monetary growth with accommodation fiscal policies in a small open economy. Joumal of International Monev and Finance 6. 179- 193.

Viner, J. (1937) Studies in the Theory of International Trade. Harper, New York.

Viner, J. (1948) Power versus plenty as objectives of foreign policy in the seventeenth and eighteenth centuries. World Politics 1, 1-29. Reprinted in Essays on the Intellectual Histony of Economics, by J. Viner; edited by D.A. Irwin, Princeton University Press, 1991.

Vincr. J. (1968) Mercantilist thought. In: The International Encyclopedia of the Social Sciences, ed D. Sills, Vol. 4. pp. 435-443, Macmillan and the Free Press, New York. Reprinted in Essays on the Intellectural History of Economics, by J. Viner; edited by D.A. Irwin, Princeton University Press, 1991.

Zou, H. (1991) Socialist economic growth and political investment cycles, European Journal of Political Economy 7, 141-157.

Zou, H. (1994a) Short-run analysis of fiscal policies and the current account in a finite horizon model. Journal of Macroeconomics 16, 347-357.

Zou, H. (1994b) The spirit of capitalism and long-run growth. European Journal of Political Economy 10, 279-293.

Zou, H. (1995a) A dynamic model of capital and arms accumulation. Journal of Economic Dynamics and Control 19, 371-393.

Zou, H. (1995b) The spirit of capitalism and savings behavior. Journal of Economic Behavior and Organization 28, 131-143. 